\title{
A PRÁTICA DO CICLISMO EM CLUBES DE PORTO ALEGRE/RS
}

\section{Tiago Oviedo Frosi}

Universidade Federal do Rio Grande do Sul, Porto Alegre, Rio Grande do Sul, Brasil

\section{Lucas Lopez da Cruz}

Universidade Federal do Rio Grande do Sul, Porto Alegre, Rio Grande do Sul, Brasil

\section{Ronaldo Dreissig de Moraes}

Universidade Federal do Rio Grande do Sul, Porto Alegre, Rio Grande do Sul, Brasil

\section{Janice Zarpellon Mazo}

Universidade Federal do Rio Grande do Sul, Porto Alegre, Rio Grande do Sul, Brasil

\section{Resumo}

O objetivo deste estudo é reconstruir o processo de emergência da prática do ciclismo em clubes de Porto Alegre. Para tanto, foram consultadas fontes impressas, como almanaques, reportagens de revistas, jornais e alguns estudos sobre a história do esporte em Porto Alegre constantes na literatura. Em Porto Alegre no final do século XIX foram fundados dois clubes exclusivos para a prática do ciclismo: o Rodforvier Verein Blitz e a União Velocipédica. Após a aquisição de suas sedes e a construção dos velódromos, os clubes começaram a competir entre si. Assim, o ciclismo começou a ser difundido na cidade pelos clubes. No entanto, com a difusão do futebol e outras formas de lazer, o ciclismo, assim como outros esportes sofreram um abalo. Os dirigentes dos clubes ciclísticos que também eram envolvidos com outras associações esportivas parecem ter se dedicado ao salvamento de clubes ligados a outros esportes. Sem apoio, as associações ciclísticas enfraqueceram e foram fechadas em Porto Alegre entre as décadas de 1910 e 1920.

Palavras-chave: Ciclismo - Clubes - História - Esporte

\section{Considerações iniciais}

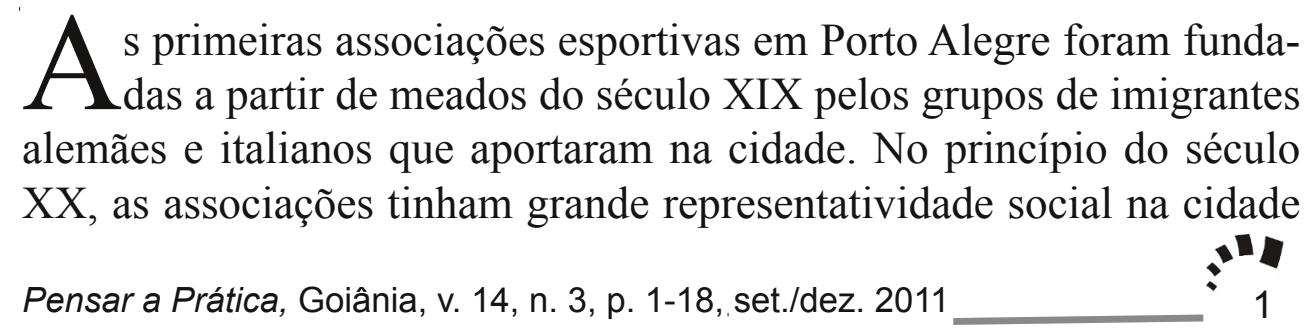


de Porto Alegre. Segundo estudo de Mazo \& Frosi (2009), durante um longo período, o associativismo esportivo desempenhou papel central na expressão das identidades culturais dos imigrantes e seus descendentes possibilitando a criação de clubes de diversas práticas como a Ginástica, o Ciclismo, o Remo, o Futebol, entre outros.

A introdução de práticas esportivas dos seus países de origem, a organização de sociedade e associações, a manutenção dos costumes e da língua da pátria mãe viva, a adoção de símbolos (bandeiras, os uniformes, entre outros) foram alguns dos meios adotados pelos grupos de imigrantes para a produção de "fronteiras simbólicas" (HALL, 1997). Essas representações culturais e práticas de significação, de acordo com Hall (1997), operam por meio da diferença, envolvendo um trabalho de marcação, como também de produção de efeitos de fronteiras simbólicas. Isso pode ser observado nas associações esportivas fundadas pelos teuto-brasileiros, os quais se apropriaram de certos elementos culturais como forma de representação de suas identidades.

Conforme estudo de Mazo; Gaya (2006), os teuto-brasileiros buscavam preservar sua identidade cultural pela difusão do método ginástico alemão, das práticas esportivas, dos festivais de ginástica e da manutenção do idioma alemão, representado pelos dialetos, dentro das novas associações. Dessa forma se encontra nos teuto-brasileiros um tipo de imigrante que formou raízes, sendo de certa forma concorrente aos ítalo-brasileiros e aos luso-brasileiros que formavam suas associações simultaneamente.

No ciclismo, os primeiros clubes foram fundados pelos teuto-brasileiros. Já os ítalo-brasileiros não chegaram a fundar uma associação própria dedicada à prática do Ciclismo, mas participaram de outras associações. É possível que isto ocorresse devido ao fato de que a comunidade ítalo-brasileira procurava aceitação na sociedade porto alegrense, predominantemente formada por teuto-brasileiros e lusobrasileiros (MAZO; FROSI, 2008). Além disso, a aceitação dos ítalobrasileiros nos clubes de teuto-brasileiros era concedida em razão da boa condição financeira de alguns descendentes de italianos.

Neste cenário do associativismo esportivo porto alegrense, esta pesquisa tem por objetivo reconstruir o processo de emergência da prática do ciclismo em clubes na cidade. Este estudo foi motivado pela ausência de estudos históricos referentes à prática do Ciclismo em Porto Alegre. Cabe referir que há a publicação de Licht (2003), um livro intitulado História do Ciclismo no Rio Grande do Sul (1896 - 
1905) que se restringe apenas a uma compilação de notícias extraídas do jornal Correio do Povo. O livro nem mesmo apresenta uma história descritiva do ciclismo em Porto Alegre, o que não tira o valor da obra enquanto catalogação de fontes documentais. No que diz respeito ao desenvolvimento histórico do ciclismo no Brasil, já há certo acúmulo de contribuições por meio dos estudos de Schetino $(2007$; 2008) e Schetino;Melo (2009), diferentemente da produção científica no Rio Grande do Sul.

Este estudo justifica-se por recuperar a memória da prática do ciclismo no cotidiano porto-alegrense buscando contribuir para futuros estudos comparativos do surgimento e desenvolvimento desse esporte entre cidades que possuíam tal prática inserida em seu quadro esportivo. Para viabilizar essa pesquisa histórica foram consultadas fontes impressas, como jornais, revistas e almanaques e alguns estudos sobre a história do esporte em Porto Alegre constantes na literatura (LICHT, 2003; MAZO, 2004; 2003; MAZO;FROSI, 2009;2008; MAZO;GAYA, 2006; ROZANO;FONSECA, 2005;). Os dados coletados nessas fontes foram submetidos à análise documental, que segundo Bardin (2000) consiste em realizar operações de desmembramento do texto em unidades de significado, buscando desvendar seus diferentes sentidos e, posteriormente, a partir da análise dos dados reagrupá-los e construir os eixos norteadores da pesquisa.

Nesse artigo abordaremos a fundação e desenvolvimento dos clubes de ciclismo em Porto Alegre até o declínio dessa prática, analisando as fontes a partir de categorias como: representações, imaginário social e fronteiras simbólicas. A partir daí buscamos apresentar evidências que apontem possíveis razões para o fim da prática de ciclismo em clubes de Porto Alegre.

\section{A criação de clubes de ciclismo em Porto Alegre}

Conhecido em todo mundo, o ciclismo teve sua prática essencialmente esportiva, separada do emprego da bicicleta como diversão ou transporte, iniciada em meados do século XIX, na Inglaterra, logo que os aperfeiçoamentos na fabricação do veículo possibilitaram o alcance de maiores velocidades (VIEIRA;FREITAS, 2007). Em 1865, já existiam na Inglaterra alguns círculos entusiastas do esporte, e vinte anos depois, com sua difusão por toda a Europa, era fundada na França, a União Ciclística Internacional. O Ciclismo faz parte do programa 
Olímpico, desde a primeira edição dos Jogos Olímpicos da Era Moderna, em Atenas 1896 (COB, 2009).

A primeira prova internacional de ciclismo foi realizada em 1869 a Paris-Rouen - e tinha um percurso de $123 \mathrm{~km}$ (MASO, 2005). O primeiro velódromo do mundo foi construído em Paris, em 1890. As competições olímpicas são realizadas em estradas e velódromos. O ciclismo olímpico possui dez categorias, com provas de velocidade, meio-fundo e resistência, divididas em provas individuais e por equipes, com disputas de velocidade, contra o cronômetro e perseguição. Segundo o COB (Comitê Olímpico Brasileiro) o esporte é dividido em quatro modalidades: pista, estrada, mountain bike e BMX. A categoria pista tem o maior número de provas: dez diferentes; na estrada há duas provas, de velocidade e contra o relógio; na mountain bike há apenas uma, a cross-country; a BMX, versão ciclística do motocross, também tem apenas uma prova, a de corrida em pistas com saltos e obstáculos. A participação das mulheres na competição olímpica ocorreu apenas a partir de 1988, na Olimpíada de Seul (Coréia).

O ciclismo, no Brasil, em forma de competição, começou a ser praticado em 1892, quando foi construído um o Velódromo Nacional no Rio de Janeiro (JESUS, 1999; ARAÚJO, 1995). Em 1895 foi construído um velódromo precário no Parque do Ibirapuera em São Paulo, realizando-se a primeira prova em sua inauguração, marcando a difusão da modalidade nos maiores centros do país (VIEIRA; FREITAS, 2007). No Rio Grande do Sul, mais precisamente em Porto Alegre, em 1869 , tem-se o registro do primeiro ciclista em solo gaúcho que foi o Sr. Alfredo Dillon (LICHT, 2003). Quase três décadas depois foi fundada a primeira associação de ciclistas em Porto Alegre pelos imigrantes alemães em 1896: Rodforvier Verein Blitz (LICHT, 2003), mais uma vez, os teuto-brasileiros afirmavam sua identidade através das práticas esportivas (MAZO;FROSI, 2009; OLIVEIRA, 1987; DAUDT, 1952).

Antes, uma significativa alteração geográfica e dos hábitos citadinos em Porto Alegre ocorreu com a introdução dos bondes puxados a burro pela Companhia Carris Porto-Alegrense em 1873. No entanto, durante os primeiros vinte anos de vida da Companhia, tais bondes só dirigiam-se aos bairros Menino Deus, Navegantes e Partenon. Não obstante, uma empresa concorrente iniciou operações em 1891. A Companhia Carris Urbanos apresentava veículos bem menores, por isso apelidado de caixas de fósforo. Esta passou a estabelecer linhas pa- 
ra bairros que estavam surgindo, como o Independência, Moinhos de Vento e Floresta, os quais, até o momento, eram privados de transporte coletivo e apresentavam um reduzido número de moradores. Sendo assim, com o novo quadro viário da cidade e o surgimento dos "arraiais" ou arrabaldes (chamados atualmente de bairros), foram criadas as condições para o surgimento dos prados ou hipódromos, que aprimoravam, com pistas circulares ou elípticas, as antigas carreiras de cancha reta (disputadas em pista retilínea).

No entanto, não se pode creditar todo o crescimento da cidade aos animais de tração (mulas e burros) da empresa Carris. É importante destacar que as duas companhias de bondes se fundiram a partir de 1908/1909 e evoluíram para a importante conquista da tração elétrica. O bonde de tração elétrica diminuiu as distâncias e os tempos de viagens, segundo Rozano;Fonseca (2005), o que se constituiu como um fator decisivo para o crescimento e desenvolvimento de todos os bairros. Foi um período de intensificação do processo de urbanização (PIMENTEL, 1945).

Um dos aspectos que pode ter favorecido a criação da Rodforvier Verein Blitz no ano de 1896 foi o interesse da "elite" porto-alegrense de organizar novos espaços de socialização e preservação de sua identidade cultural. Após passar por um período de estruturação, a associação promove em 1897 a primeira corrida ciclística nas ruas de Porto Alegre, pois ainda não possuía um velódromo, que veio a ser concluído no ano seguinte (LICHT, 2003). Em 1898, após a conclusão do velódromo, a Blitz promoveu a primeira corrida ciclística em pista oficial em Porto Alegre. Provavelmente foi esta competição que estimulou a fundação de uma nova associação de ciclistas, constituída em sua maioria por teuto-brasileiros, chamada União Velocipédica, em 1899. Nascia aqui um concorrente a altura das aspirações da Blitz, porém com uma identidade um pouco diferente. Por imposições sociais, a Blitz não aceitava membros que não fossem teuto-brasileiros, enquanto a União Velocipédica, apesar de na sua maioria ser composta por imigrantes alemães, aceitava imigrantes italianos como associados. Isso se deveu a qualidade desses atletas nas disputas em duas rodas. $\mathrm{O}$ uso do dialeto alemão nas atas, documentos e instruções orais dos treinamentos caracterizava, ainda assim, a produção de fronteiras simbólicas nesses clubes (MAZO; GAYA, 2006).

O marco da fundação desse novo clube, a União Velocipédica, foi a construção do seu velódromo em 1899, localizado no terreno locado 
pelo município de Porto Alegre, no Campo da Várzea. O terreno, onde hoje se situa o Instituto Parobé (Engenharia Mecânica da Universidade Federal do Rio Grande do Sul) ficava próximo a Rua Conceição, em frente ao local onde atualmente estão o prédio da Arquitetura e o prédio da reitoria da UFRGS. Há indícios de que os integrantes da União Velocipédica já se reuniam de modo informal antes de 1900 com o intuito de promover excursões e passeios turísticos que partiam do Campo da Várzea até o bairro Belém Velho. Esses passeios, que chagavam a contar com a participação de aproximadamente mil ciclistas que pedalavam para desfrutar das belezas naturais do Lago Guaíba. O clube, até então, se autodenominava União Velocipédica de Amadores (LICHT, 2003). Após esse período, a associação já estabelecida, realizava eventos e encontros que eram divulgados em jornais e convites. No exemplar dos dias 3 e 31 de janeiro de 1900, disponíveis no acervo do Memorial Histórico do Rio Grande do Sul (localizado em Porto Alegre) constam a divulgação de corridas ciclísticas e festejos de Carnaval realizados pela União Velocipedica.
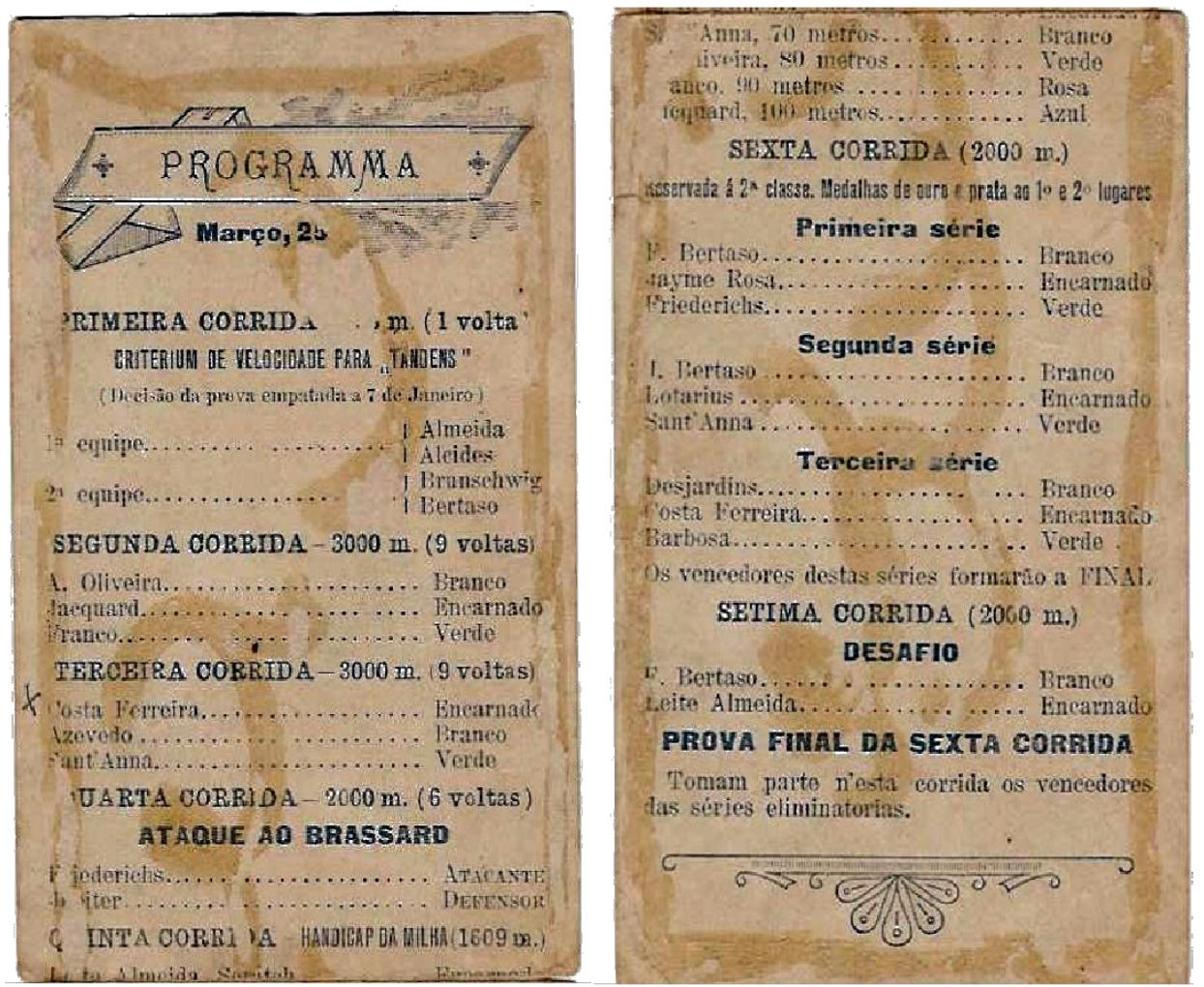

Figura 1: Programação de corridas da União Velocipedica de 25 de março de 1900. Fonte: Acervo pessoal de Arnaldo Willy Becker 
O velódromo da União Velocipédica localizava-se na esquina da Rua Sarmento Leite com a Rua Osvaldo Aranha, tendo sido inaugurado em 1899, mesma ocasião em que desfilou o primeiro automóvel visto em Porto Alegre, pertencente ao senhor Schartz. Rozano;Fonseca (2005) apontam que na virada do século XIX para o XX, Porto Alegre chegou a contar com dois velódromos, clubes de ciclismo, e cultivava as corridas de bicicleta. O ciclismo teve a virtude de atrair as mulheres ao esporte. Nas grandes corridas que então se organizaram houve competições femininas específicas, apesar das dificuldades das mangas largas e das saias-balão que a moda e o recato faziam obrigatórias.

Em 1900, Porto Alegre passava por inúmeras mudanças e transformações com a intendência municipal nas mãos de José Montaury (apoiado pelo então Governador do Estado do Rio Grande do Sul, Borges de Medeiros). Para se ter idéia do crescente número de prédios construídos na cidade, nos anos de 1902/1903, o município obteve 235 licenciamentos de novas construções. Já nos anos de 1911/1912, o número de licenciamentos prediais foi de 1590. Somando todas as construções que foram registradas no período de 1903 a 1912, a cidade possuía 6060 novos prédios legalizados (FRANCO, 2000).

Segundo Costa (1997, p.114), "Porto Alegre permaneceu provinciana nos primeiros anos do século. Seu crescimento não foi acompanhado de um plano urbanístico de infra-estrutura". Nesse período havia 73 mil habitantes na cidade, como afirma Borges (apud Costa, 1997, p.114):

É um período efervescente, [ ... ] em que o advento do capitalismo é acompanhando de mudanças como o fim da escravidão, a chegada de europeus, o surgimento do trabalho assalariado, a industrialização, a urbanização e a emergência de novas classes - a burguesia incipiente e o nascente proletariado.

No período onde tivemos a chegada de muitos grupos de italianos, e conseqüentemente o período onde se iniciaram a fundação de diversas associações ligadas a este grupo, que promoviam a chamada italianitá (MAZO; FROSI, 2008), havia um grupo positivista no poder. A onda de modernização e construção de diversos prédios que marcaram a cidade (obras promovidas pelo próprio governo do Estado) proporcionou a possibilidade de que surgissem as instalações das novas agre- 
miações e clubes de Porto Alegre. A comunidade italiana preparava, assim, sua afirmação cultural dentro do campo esportivo, já fortemente influenciado pelos teuto-brasileiros.

Nas competições de ciclismo as disputas se acirravam cada vez mais, devido às questões culturais que envolviam os dois clubes ciclísticos da cidade, principalmente pelas visões diferentes relacionadas às regras de associação. Nesse aspecto uma equipe, a Blitz, primava pela manutenção da cultura alemã em seus registros, enquanto que a União Velocipédica, apesar de sua origem teuto-brasileira, abriu espaço para bons ciclistas de outras etnias, principalmente ítalo-brasileiros. Além disso, como em outros campos, muitas vezes a religiosidade predominantemente católica romana dos descendentes de italianos e portugueses se configurava como um aspecto conflituoso em relação ao culto protestante comum entre os descendentes de alemães. Esse choque de identidades criava diversas fronteiras junto a outros aspectos citados.

Em 1900 iniciam-se as disputas ciclísticas no âmbito estadual, que passaram a ser realizadas anualmente popularizando o ciclismo em Porto Alegre e em todo Estado (FRANCO, 2000). Havia um grande número de ciclistas tanto na Sociedade Blitz como na União Velocipédica e os eventos eram divulgados atravpés de convites (Imagem 3). O público porto-alegrense comparecia aos velódromos para assistir as competições que tinham um aspecto festivo (REVISTA DO GLOBO, 1936, p. 15 apud MAZO, 2004).

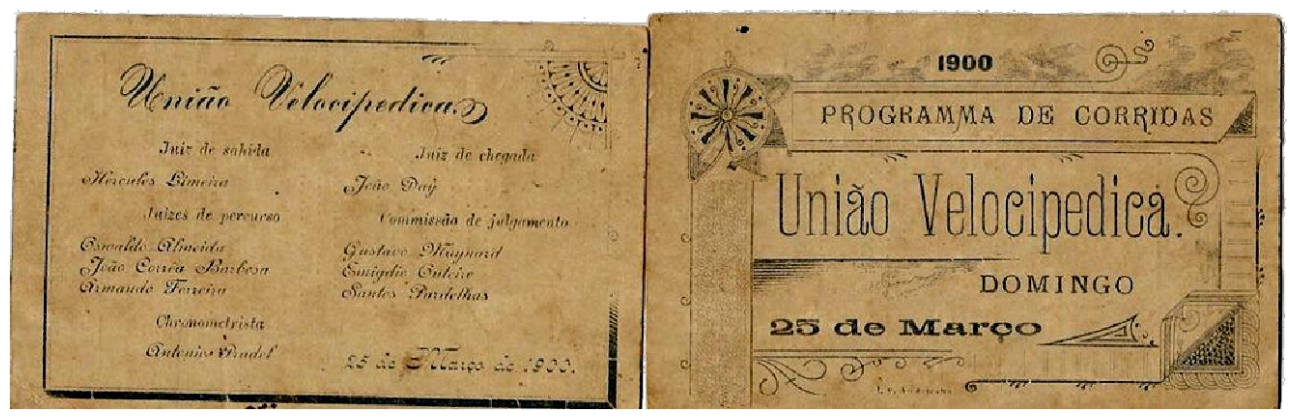

Figura 2: Frente e verso do convite com programação de corridas da União Velocipedica de 25 de março de 1900.

Fonte: Acervo pessoal de Arnaldo Willy Becker

Entre os competidores de maior destaque, podemos citar a figura de João Ribeiro Alves, campeão das disputas em 1898 e 1901, tendo disputado a prova pelos dois clubes. Como a maioria dos atletas que 
viviam de outros meios e se dedicavam ao esporte de forma amadora, João Alves era Capitão do Corpo de Bombeiros da Brigada Militar da cidade de Porto Alegre.

\section{O declínio do ciclismo em Porto Alegre}

Curiosamente, todos os membros da Blitz eram também associados ao Ruder Verein Germania, um dos mais populares clubes de remo de Porto Alegre na época. Pouco mais de uma semana depois da partidaexibição do Sport Club Rio Grande (primeiro clube de futebol do Brasil) em Porto Alegre no dia 07 de setembro de 1903 (DACOSTA, 2005), um grupo de amigos resolveu fundar um clube de futebol, chamando-o de Fussball Club Porto Alegre (MAZO, 2003). No mesmo dia, foi fundado outro clube que se tornaria um dos principais do Estado do Rio Grande do Sul, o Grêmio Foot-ball Porto Alegrense. Os fundadores do Fussball foram Leopoldo Rosenfeld (presidente), J. Brenner (secretário), O. Becker (tesoureiro), Hugo Brenner, Oscar Schaitza, Guilherme Trein, Rodolpho Schoeller, Eugênio Sattler, Oscar Matte, Rodolpho Campani, Walter Heckmann, Ernesto Oswaldo Schmitt, Otto Niemeyer, Reynaldo Schoeller, Hugo Gerdau, Alfredo Stumpf, Hugo Becker e Francisco Strattmann, todos estes ciclistas da Blitz (AMARO JÚNIOR,1942). Os sobrenomes dos fundadores evidenciam a presença dos teuto-brasileiros no clube.

Cabe salientar que o Fussball Club não aceitava em seu elenco indivíduos de origem que não fosse a alemã. Já o Grêmio Foot-ball Porto Alegrense foi fundado no Salão Grau (restaurante de um hotel da região central da cidade) por 32 homens de origem predominantemente teuto-brasileira. Carlos Luiz Bohrer foi, então, eleito o primeiro presidente do clube. O Grêmio permitia a participação de pessoas de outros segmentos étnicos, desde que estas comprovassem uma condição econômica e social elevada (ASPIS, 2006).

Então, em 1910 o Fussball participa da fundação da Liga de FootBall Porto Alegrense, disputando o campeonato municipal. Ao final do campeonato seguinte, em julho de 1911, o clube perdeu seu lugar na Rua Voluntários da Pátria, onde foi criada sua sede. Campelo (2005) afirma que no final da década de 1910, Porto Alegre possuía sete clubes. Eram eles: Grêmio Foot-Ball Porto Alegrense, Fuss-Ball Club Porto Alegre, Sport Club Internacional, Militar Football Club, FussBall Manchaft Frisch Auf (mais conhecido como Frisch Auf, que foi 
absorvido pela Turnerbund, a atual SOGIPA), Grêmio Foot-Ball Sete de Setembro e o Sport Club Nacional. A Sociedade Blitz já não existia mais, e a Prefeitura de Porto Alegre estava abrindo várias ruas novas transversais a Voluntários da Pátria, o que colabora para a questão também levantada por este estudo, que aponta para o processo e urbanização da cidade como algo que contribuiu para a diminuição do ciclismo em clubes. Entre essas obras, estava a da Rua Almirante Tamandaré, que cortou o campo do Fussball ao meio. Com a perda de seu campo, o Fussball transferiu-se para um terreno na Rua Benjamin Constant, nos arrabaldes (ou bairro) de São João (OLIVEIRA,1912).

Com o primeiro velódromo da Blitz construído no Parque Moinhos de Vento, junto ao Hipódromo Independência (PEREIRA, 2008), e com a sede social na Rua Voluntários da Pátria, o clube tinha então dois locais de prática esportiva e social. Com a criação da Associação Protetora do Turf, em 1909, o Prado Independência torna-se a pista oficial de corridas de cavalo da cidade. As fontes sugerem que o ciclismo, assim, perdeu força na região devido a esse jogo de interesses, onde a Protetora do Turf pretendia controlar exclusivamente o local, já que a área era muito valorizada, inclusive para loteamentos (MAZO;FROSI, 2009; PEREIRA, 2008). O velódromo acabou saindo desse terreno no início do da década de 1910. O departamento de ciclismo passou então a funcionar na sede da Rua Voluntários da Pátria. Nesse período, o campo do Grêmio, vizinho ao hipódromo, começava a superlotar, pressionando as adjacências a cederem espaços para a construção de novos pavilhões (utilizados como arquibancadas na época). A construção do primeiro pavilhão, em 1912, só se deu após o cercamento do campo (ACKER;VIEIRA, 2008; NEVES, 2008). Ainda foram construídos outros dois pavilhões, um, em 1918, anos após a saída do velódromo da Blitz e outro em 1944, após a derrota política da Protetora do Turf e saída do Hipódromo que se instalou no Cristal através do Decreto Lei Municipal $\mathrm{n}^{\circ} 140$, de 20/11/1942. Além disso, em 1910 a prefeitura municipal de Porto Alegre decidiu tomar judicialmente o prédio da União Velocipedica situado no atual Parque Farroupilha, como evidenciado no trecho da reportagem do jornal "Zero Hora" de 30/07/1910:

Sabemos que a intendencia Municipal vai tomar posse judicialmente do edifício da União Velocipedica, situado no Campo da Redempção [Parque Farroupilha], e actualmente occupado pelo 
Club Gymnastico Rio-Grandense, que o arrendou. A Intendencia allega que a União Velocipedica infringiu clausulas do respectivo contrato.

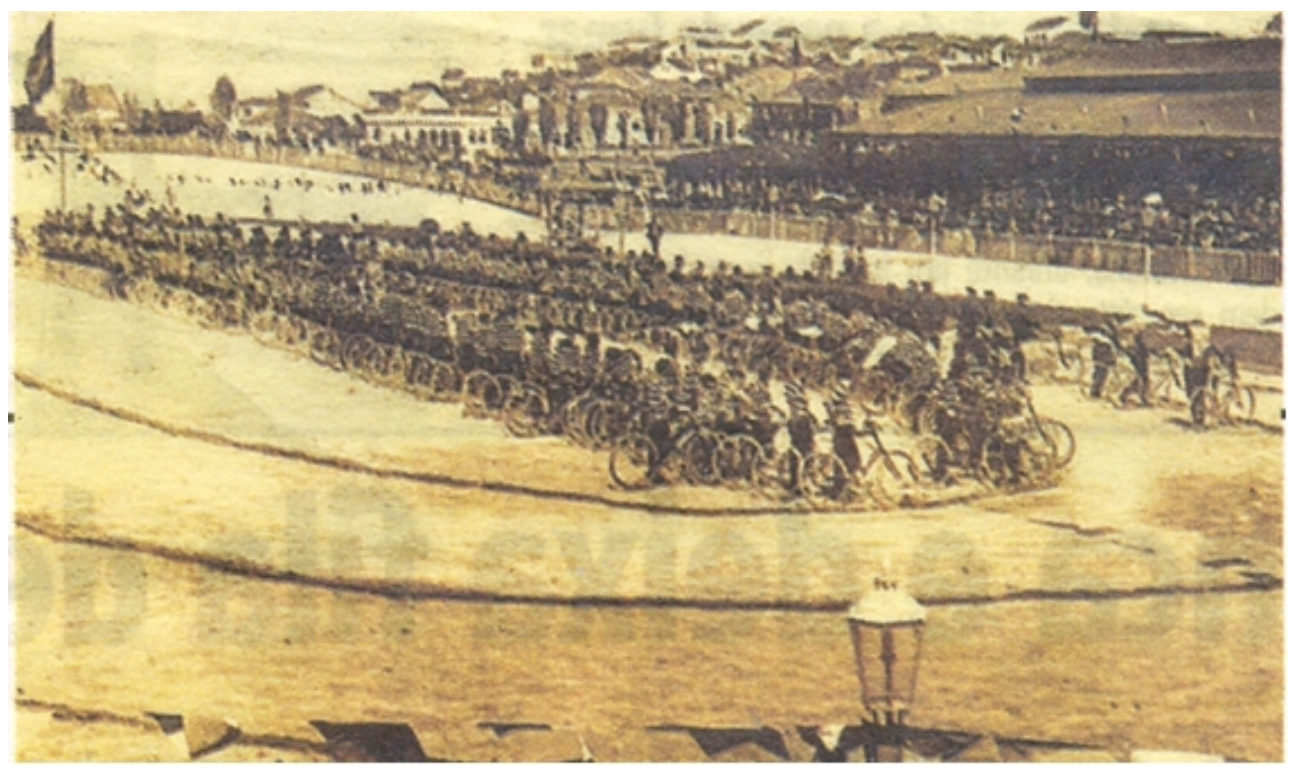

Figura 3: Foto do velódromo municipal no Parque Farroupilha.

Fonte: Jornal Correio do Povo de 30/07/1910.

Um resumo dos movimentos das instalações esportivas pode ser acompanhado com mais clareza no quadro 1:

\begin{tabular}{|c|c|c|c|c|c|}
\hline & $\begin{array}{l}\text { Rodforvier } \\
\text { Verein Blitz }\end{array}$ & $\begin{array}{c}\text { União } \\
\text { Velocipédica }\end{array}$ & $\begin{array}{c}\text { Fussball Club } \\
\text { Porto Alegre }\end{array}$ & $\begin{array}{c}\text { Grêmio } \\
\text { Foot-Ball } \\
\text { Porto } \\
\text { Alegrense }\end{array}$ & $\begin{array}{c}\text { Prado } \\
\text { Independência }\end{array}$ \\
\hline Fundação & 1896 & 1895 & 1903 & 1903 & 1894 \\
\hline Fechamento & $\begin{array}{c}\text { Meados de } \\
1910\end{array}$ & $\begin{array}{c}\text { Meados de } \\
1910\end{array}$ & 1944 & $\begin{array}{c}\text { Em } \\
\text { funcionamento }\end{array}$ & 1959 \\
\hline $\begin{array}{c}\text { Construção da } \\
\text { Sede }\end{array}$ & 04/09/1898 & 19/11/1899 & 1903 & 1910 & 1894 \\
\hline Localidade & $\begin{array}{c}\text { Parque } \\
\text { Moinhos de } \\
\text { Vento (atual) }\end{array}$ & $\begin{array}{c}\text { Parque } \\
\text { Farroupilha } \\
\text { (atual) }\end{array}$ & $\begin{array}{c}\text { Rua } \\
\text { Voluntários da } \\
\text { Pátria }\end{array}$ & $\begin{array}{c}\text { Parque } \\
\text { Moinhos de } \\
\text { Vento (atual) }\end{array}$ & $\begin{array}{c}\text { Parque } \\
\text { Moinhos de } \\
\text { Vento (atual) }\end{array}$ \\
\hline $\begin{array}{c}\text { Ano da } \\
\text { Mudança }\end{array}$ & 1910 & - & $\begin{array}{c}\text { Década de } \\
1910\end{array}$ & 1954 & 1942 \\
\hline $\begin{array}{c}\text { Nova } \\
\text { Localidade }\end{array}$ & $\begin{array}{c}\text { Rua } \\
\text { Voluntários da } \\
\text { Pátria }\end{array}$ & - & - & $\begin{array}{c}\text { Bairro Azenha } \\
\text { (atual) }\end{array}$ & $\begin{array}{c}\text { Bairro Cristal } \\
\text { (atual) }\end{array}$ \\
\hline
\end{tabular}

Quadro 1: Eventos relevantes

Pensar a Prática, Goiânia, v. 14, n. 3, p. 1-18, set./dez. 2011 
Outro provável motivo do declínio dos velódromos em Porto Alegre seria a diminuição da prática do ciclismo na cidade em decorrência do incremento do trânsito de veículos nas ruas da atual capital do Rio Grande Sul, além de muitas mudanças com relação aos espaço livres para prática esportiva e parques da capital (OLIVEIRA, 1912). Esse fator não afetou diretamente outras práticas esportivas como o remo, que ao contrário do ciclismo acabou favorecido nesse processo. Os clubes de remo foram transferidos para outro bairro mais distante do centro da cidade, onde atualmente fica o cais do porto (MAZO; FROSI, 2008). A construção desse parque náutico foi ocasionado pelo processo de urbanização, que ao mesmo tempo resultou na construção de ruas e avenidas onde antes estavam os velódromos e os clubes de remo, vindo também a causar uma diminuição no número de prados da cidade (instalações esportivas que ocupavam grandes áreas). Como o interesse pelo ciclismo vinha diminuindo por uma intrincada rede de influências, os velódromos vieram praticamente a acabar por completo, restando pequenas pistas em parques como o Marinha do Brasil.

Com a entrada do Brasil na II Guerra Mundial contra a Alemanha e a Itália, nas décadas de 1930 e 1940, as sociedades teuto-brasileiras e ítalo-brasileiras foram perdendo suas identidades pátrias, principalmente com relação aos seus nomes e suas regras institucionais, o que fez o movimento clubístico perder força dentro de Porto Alegre (MAZO;FROSI, 2008). Como se a influência importante do futebol na cultura esportiva da cidade não fosse suficiente, a repressão (muitas vezes velada) ao associativismo dos imigrantes europeus parece ter sido o golpe final no ciclismo.

\section{Considerações finais}

A contribuição dos imigrantes alemães e italianos foi fundamental à prática do ciclismo em Porto Alegre. Estes grupos sociais tiveram a iniciativa de fundar os dois primeiros clubes de ciclismo na cidade no final do século XIX: a Rodforvier Verein Blitz e a União Velocipédica. Posteriormente, as associações de ciclistas construíram seus velódromos. O Blitz ficou situado na parte central do Prado da Independência (atual Bairro Moinhos de Vento) e o da União Velocipédica localizavase na Várzea (atual Parque Farroupilha e parte do Campus Central da UFRGS).

A ascensão do ciclismo foi marcante até o início do século $\mathrm{XX}$, 
ocorrendo competições e provas nos velódromos da cidade. No mesmo período começaram a surgir os primeiros clubes de futebol em Porto Alegre, os quais gerariam um novo foco de interesse. Cabe referir que o remo também dividia a atenção dos espectadores com o ciclismo e o futebol. Além dos esportes, outras formas de lazer, como por exemplo, o cinema se constituiu em um dos elementos de uma complexa rede de influências para o declínio da atividade ciclística em Porto Alegre.

As mudanças no cenário urbano, também acabaram por enfraquecer o ciclismo na cidade. $\mathrm{O}$ desenvolvimento gradual dos bairros onde se localizavam os clubes e velódromos, o incremento do trânsito da capital, a extinção dos prados, o deslocamento do prado Independência para uma região distante na época, e a popularização do futebol fez com que o ciclismo fosse perdendo a força que o consagrou, tendo a sua prática diminuída de forma significativa.

Após um longo processo de movimentos políticos que visavam a modernização da cidade, principalmente na gestão de José Montaury, foram sendo construídos projetos para abertura de novas ruas na cidade em localidades antes ocupadas pelos prados. Com o declínio da popularidade das corridas de cavalo e de bicicleta que aconteciam nesses espaços esportivos, estes acabaram desativados ou mudaram de localização dando lugar a novas avenidas e estabelecimentos comerciais da cidade. Um destes prados deu lugar ao que seria por muitos anos a sede do Grêmio Foot-Ball Porto Alegrense, conhecido como Estádio da Baixada, localizado no parque Moinhos de Vento de Porto Alegre.

Com a maioria dos esportes entrando em crise devido a popularização do futebol e de outras formas de lazer, os dirigentes dos clubes ciclísticos envolvidos com outras associações de remo, de ginástica e de futebol, parece ter havido a necessidade de dedicarem-se ao "salvamento" destas outras associações, porém sem poder dedicarem-se a todas. Com isto, uma prática como o ciclismo parece ter tido um declínio mais acentuado devido ao somatório de influências contrárias ao seu desenvolvimento. Somou-se ao interesse do grande público pelo futebol os revezes advindo da urbanização, com a abertura de novas ruas e avenidas, ocupadas então pelos bondes e automóveis, e redução dos espaços de prática, que pesaram fortemente no fim da modalidade em sua forma competitiva.

Como as fontes apontam para a prática do ciclismo em Porto Alegre ser realizada, nos seus primórdios, como forma de lazer, onde 
ocorriam passeios ciclísticos em grandes grupos e, posteriormente, inserindo-se na lógica da atividade esportiva para o desenvolvimento "pregada" pelos alemães, a aposta monetária parece não ter sido um elemento presente no ciclismo da cidade. Como a prática da aposta em dinheiro parece ter impulsionado o ciclismo em outras cidades, podemos refletir sobre uma possível causa do desinteresse pelo esporte: a defesa de um "éthos amador" que se enfraquece pela falta de elementos que criem uma tensão agradável entre os atletas e para o público. Inclusive, há evidências de que as associações de ciclismo tiveram conflitos com a prefeitura municipal ao final da década de 1910 em razão da cobrança de taxas e brigas judiciais pelo terreno onde situava-se um prédio da União Velocipedica, como citado anteriormente.

Porto Alegre também começou a contar com outras formas de entretenimento ao público, como o cinema, tornando o ciclismo apenas mais uma opção. Abandonado aos poucos pelo público, e com dificuldades de manter seu espaço entre os clubes, principalmente pela área que ocupavam seus velódromos, o esporte foi sofrendo uma grande perda de contingente. Com esse enfraquecimento, e sem a força necessária para sobreviver, diferente das associações de turfe que puderam se apoiar na Associação Protetora do Turfe e das associações de remo que tinham a ajuda da Liga Náutica, os clubes ciclísticos foram fechados, e Porto Alegre deu fim a essa prática em clubes.

\title{
The cycling practice in clubs of Porto Alegre/Brazil
}

\begin{abstract}
The objective of this study is to reconstruct the emergency process of the cycling practice in clubs of Porto Alegre. This research was developed through peruse in printed sources like almanacs, journals, magazine's notices and the academic production. In the 19th century's Porto Alegre were established two cycling clubs: Rodforvier Verein Blitz and União Velocipédica. After their headquarters and velodrome construction, this clubs begins competition. Cycling was spread on the city by the clubs. However, football and other leisure practices spread influenced the cycling and other sports weakening. The cycling club officials that are involved with other sports associations appeared to actuate on saving these other associations, but not the cycling ones. Without support, cycling clubs of Porto Alegre weakens and are closed between 1910 and 1920.
\end{abstract}

Keywords: Cycling - Clubs - History - Sport 


\section{La práctica de ciclismo en los clubes de Porto Alegre/Brasil}

\section{Resumen}

El objetivo de este estudio es reconstruir el proceso de surgimiento de la práctica del ciclismo de clubes en Porto Alegre. Se ha consultado fuentes impresas, tales como almanaques, artículos de revistas, periódicos y la erudición sobre el deporte en Porto Alegre. En Porto Alegre, en el siglo XIX se fundaron dos clubes exclusivos para la práctica del ciclismo: el Rodforvier Verein Blitz y la Unión Velocipédica. Tras la adquisición de su sede y la construcción de velódromos, los clubes comenzaron a competir entre sí. Así, el ciclismo comenzó a difundirse por los clubes en la ciudad. Sin embargo, con la difusión del fútbol y otras formas de ocio, el ciclismo, al igual que otros deportes han sufrido una conmoción cerebral. Los dirigentes de los clubes de ciclismo que participaron también con otras asociaciones deportivas parecen haber sido dedicados al rescate de los clubes ligados a otros deportes. Sin el apoyo, las asociaciones se debilitarán y el ciclismo de clubes se cerró en Porto Alegre entre los años 1910 y 1920.

Palabras clave: Ciclismo - Clubes - Historia - Deporte

\section{Referências}

ACKER, A.; VIEIRA I. Da Baixada à Arena: Grêmio sai do Olímpico para seguir crescendo. Portal Clic RBS - Sessão de Esportes. Porto Alegre: 28 dez. 2008. Disponível em: www.clicrbs.com.br/esportes/rs/, Acesso em 28 dez 2009.

AMARO JÚNIOR, J. (org.). Almanaque Esportivo do Rio Grande do Sul. Porto Alegre: Tipografia Esperança, Primeiro Ano, 1942.

ARAÚJO, R. A vocação do prazer: a cidade e a família no Rio de Janeiro republicano. Rio de Janeiro: Rocco, 1995.

ASPIS, A. Futebol Brasileiro: do início amador à paixão nacional. Porto Alegre: Evangraf, 2006.

BARDIN, L. Análise de Conteúdo. Lisboa: Edições 70, 2000.

BURKE, P. O que é História Cultural. Rio de Janeiro: Jorge Zohar Editora, 2008.

CAMPELO, E. Futebol Gaúcho: Grandes times e craques inesquecíveis. Porto Alegre: Secretaria Estadual da Cultura do Rio Grande do Sul, 2005. 
COB, Comitê Olímpico Brasileiro. Ciclismo. Portal do Comitê Olímpico Brasileiro. Disponível em: http://www.cob.org.br/esportes/esporte.asp?id=27, acesso em $30 \mathrm{dez} .2009$.

COSTA, E. (Ed.). História Ilustrada de Porto Alegre. Porto Alegre: Já Editores, 1997.

DACOSTA, L. Atlas do Esporte no Brasil. Rio de Janeiro, Shape, 2005; disponível em: http://www.atlasesportebrasil.org.br, acesso em 3 out. de 2008.

DAUDT, J. Brasileiros de cabelos loiros e olhos azuis. Porto Alegre: Gráfica Catos, 1952.

FRANCO, S. Porto Alegre: guia histórico. Porto Alegre: Editora da UFRGS, 1998.

FRANCO, S. Gente e espaços de Porto Alegre. Porto Alegre: Editora da UFRGS, 2000.

HALL, S. The spectable of the other. In: HALL, S. Representation: cultural representations and signifying practices. Londres: Sage/The Open University, 1997.

JESUS, G. Do espaço colonial ao espaço da modernidade: os esportes na vida urbana do Rio de Janeiro. Scripta Nova - Revista Electrónica de Geografía y Ciencias Sociales. Barcelona: Universidad de Barcelona, ago. 1999, n. 45 , v. 7.

LICHT, H. História do Ciclismo no Rio Grande do Sul (1896 1905). Editora UFRGS, 2003.

MASO, B. The Sweat of the Gods: Myths and Legends of Bicycle Racing. Mousehold Press, 2005.

MAZO, J. Catálogo do Esporte e da Educação Física Na Revista do Globo. CD-ROOM. Porto Alegre: PUCRS, 2004.

MAZO, J. A emergência e a expansão do associativismo desportivo em Porto Alegre (1867-1945): espaço de representação da identidade cultural teuto-brasileira. Tese (Doutorado em Ciência do Desporto) Faculdade do Desporto, Universidade do Porto, Portugal, 2003. 
MAZO, J.; FROSI, T. Cannotieri Ducca degli Abruzzi (1908-1963): A nacionalização do 'Clube de Remo dos Italianos' em Porto Alegre. Revista Mouseion. Acervo Histórico La Salle: jan-jun, 2008. v. 2, n. 3

MAZO, J.; FROSI, T. Em busca da identidade luso-brasileira no associativismo esportivo em Porto Alegre no princípio do século XX. Revista Brasileira de Ciências do Esporte. Campinas: Autores Associados, jan/2009, v. 30, n. 2, p. 57-72.

MAZO, J.; GAYA, A. As associações Esportivas em Porto Alegre, Brasil: espaço de representação da identidade cultural teuto-brasileiro. Revista Portuguesa de Ciência e Desporto, maio 2006, v. 6, n. 2, p. 205-213.

MELO, V. Corpos, bibicletas e automóveis: outros esportes na transição dos séculso XIX e XX. In PRIORE, M.; MELO, V. (orgs.). História do Esporte no Brasil: do Império aos dias atuais. São Paulo: Editora UNESP, 2009.

NEVES, M. História do Grêmio Foot-ball Porto Alegrense. 2008. Disponível em: http://www.gremio.net/page/view.aspx?i=id_767\&language $=0$. Acesso em: em 11 de agosto de 2008 .

OLIVEIRA, O. Guia de Football (Association). Pelotas: Officinas da Livraria Universal, 1912.

OLIVEIRA, P. A imigração alemã e a introdução do punhobol no Rio Grande do Sul. Dissertação de Mestrado. PPGCMH/UFSM. Santa Maria, 1987.

PEREIRA, E. A prática do Turfe em Porto Alegre (1875/1910): alguns tropeços em meio a um vitorioso galope. Trabalho de Conclusão de Curso (Graduação). Licenciatura em Educação Física. Escola de Educação Física - UFRGS. Porto Alegre: UFRGS, 2008.

PESAVENTO, S. História \& História Cultural. $2^{\text {a }}$ ed. Belo Horizonte: Autêntica, 2008.

PIMENTEL, F. Aspectos Gerais de Porto Alegre. Imprensa Oficial. Porto Alegre, 1945. 
ROZANO, M.; FOnSECA, R. (Orgs.). História de Porto Alegre: Jockey Club. Porto Alegre: Nova Prova, 2005.

SCHETINO, A. Do Tour de France ao Velódromo Nacional: o ciclismo em Paris e no Rio de Janeiro na transição dos séculos XIX e XX. In: MELO, V. A. História Comparada do Esporte. Rio de Janeiro: Shape, 2007.

SCHETINO, A. Pedalando na modernidade: a bicicleta e o ciclismo na transição dos século XIX e XX. Rio de Janeiro: Apicuri, 2008

SCHETINO, A.; MELO, V. A bicicleta, o ciclismo e as mulheres na transição dos séculos XIX e XX. Estudos Feministas. Florianópolis: jan.-abr. 2009. v. 17, n. 1. Disponível em: http://www.scielo.br/scielo.php?pid=S0104-026X2009000100007\&script=sci_arttext.

VIEIRA, S.; FREITAS, A. O que é Ciclismo: História, Regras e Curiosidades. Rio de Janeiro: Casa da Palavra. COB, 2007.

Recebido em: 02/05/2010

Revisado em: 15/06/2010

Aprovado em: 02/09/2010

\section{Endereço para correspondência}

tiago.frosi@yahoo.com.br

Tiago Oviedo Frosi

Universidade Federal do Rio Grande do Sul

Escola Superior de Educação Física

Rua Felizardo, 750

Jardim Botânico

90690-200 - Porto Alegre, RS - Brasil 